Eur Neurol 2005;53:96-97

DOI: $10.1159 / 000085507$

\section{Posterior Fossa Tremor Induced by HIV-Associated Progressive Multifocal Leukoencephalopathy}

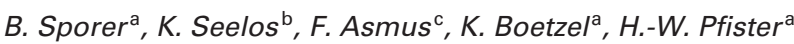

Departments of a Neurology, ${ }^{b}$ Neuroradiology,

Ludwig Maximilians University, Munich, ${ }^{\circ}$ Department of

Neurology, University of Tübingen, Tübingen, Germany

\section{Introduction}

Movement disorders occur in 2-3\% of patients with AIDS and are mostly caused by toxoplasmosis abscesses [1]. However, other rare etiologies such as progressive multifocal leukoencephalopathy (PML) or human immunodeficiency virus (HIV)-associated dementia have been described $[2,3]$. The diagnosis of PML is supported by typical MRI findings and the detection of JC virus (JCV) DNA in the cerebrospinal fluid (CSF) [4]. The lesions are mostly located in the parietal and occipital regions. Isolated infratentorial PML lesions have been reported, but they are a very rare finding in HIV-infected patients [5]. We report on an AIDS patient who presented with right-sided posterior fossa tremor in all probability due to an isolated infratentorial PML lesion.

\section{Case Report}

A 35-year-old HIV-infected German man presented with a slowly progressive unstableness and diplopia. Three months later, the physical examination showed a persistent rest, postural and kinetic tremor of the right hand, bilateral saccadic eye movements and a dissociated gaze nystagmus to the right, without further neurological deficits. His CD4 cell count was low ( 40 cells $/ \mathrm{ml})$, but increased $(110 \mathrm{cells} / \mathrm{ml})$ after the antiretroviral medication was closely monitored.
Neurophysiological, CSF and MRI Findings

Electroencephalographic examination and nerve conduction studies were normal. Acoustic evoked potentials showed a reduction of peak V during right-sided stimulation. Magnetic stimulation of the cerebral cortex revealed an increased central motor latency to the right arm (right $18.3 \mathrm{~ms}$, left $8.1 \mathrm{~ms}$ ). Tremor analysis showed a 4 - to $5-\mathrm{Hz}$ tremor (fig. 1).

$\mathrm{CSF}$ routine laboratory parameters were normal. Initially, CSF $\mathrm{JCV}$ (600 copies/ml) and BK virus (BKV; 200 copies/ml) had been detected by polymerase chain reaction (PCR) (real-time PCR with taqman probes). Three months later, CSF JCV PCR was negative, whereas the BKV load had increased to 1,500 copies $/ \mathrm{ml}$. Other CSF examinations including the assessment of an infection with Treponema pallidum, mycobacteria, Cryptococcus neoformans, cytomegalovirus, varicella zoster and Epstein-Barr virus were negative. CSF HIV load was low (140 copies/ml). Brain MRI revealed bilateral hyperintensities without contrast enhancement in the fluid-attenuated inversion recovery (FLAIR) sequence with localization in the mesencephalon, the posterior pons, cerebellar peduncles and slightly in the white matter of the cerebellum, as well as a slight cerebellar atrophy (fig. 2).

\section{Discussion}

The tremor in our patient was a posterior fossa tremor in all probability due to an infratentorial PML lesion. Recent studies showed that lesions of different etiology with location in the posterior fossa can induce low and high frequency tremor [6].

The etiology of the lesion was in all probability PML, because initial CSF analysis by PCR detected JCV DNA, which is a very specific and sensitive parameter. Some features of PML are unique in our patient. PML with an isolated manifestation in the posterior fossa is a very rare finding in AIDS patients, and only a few cases of PML, predominantly affecting the cerebellum, have been described in patients without immunodeficiency [7], hematological malignancies or AIDS [5]. JCV infection of cerebellar granule cell neurons was recently shown by Du Pasquier et al. [8] in a HIV-infected patient, suggesting a role for JCV in cerebellar atrophy dur-
Fig. 1. Tremor analysis. Bipolar surface recording with electrodes at a distance of $4 \mathrm{~cm}$ on the extensor digitorum communis muscle right (line 1) and left (line 3 ) and the flexor digitorum superficialis muscle right (line 2) and left (line 4). The investigation was done with the Nicolet Viking IV (Nicolet Inc., Kleinostheim, Germany); vertical point-to-point distance indicates an amplitude of $200 \mathrm{mV}$. Line 1 shows rhythmic muscle activity with a frequency of approximately $4.5-5 \mathrm{~Hz}$.

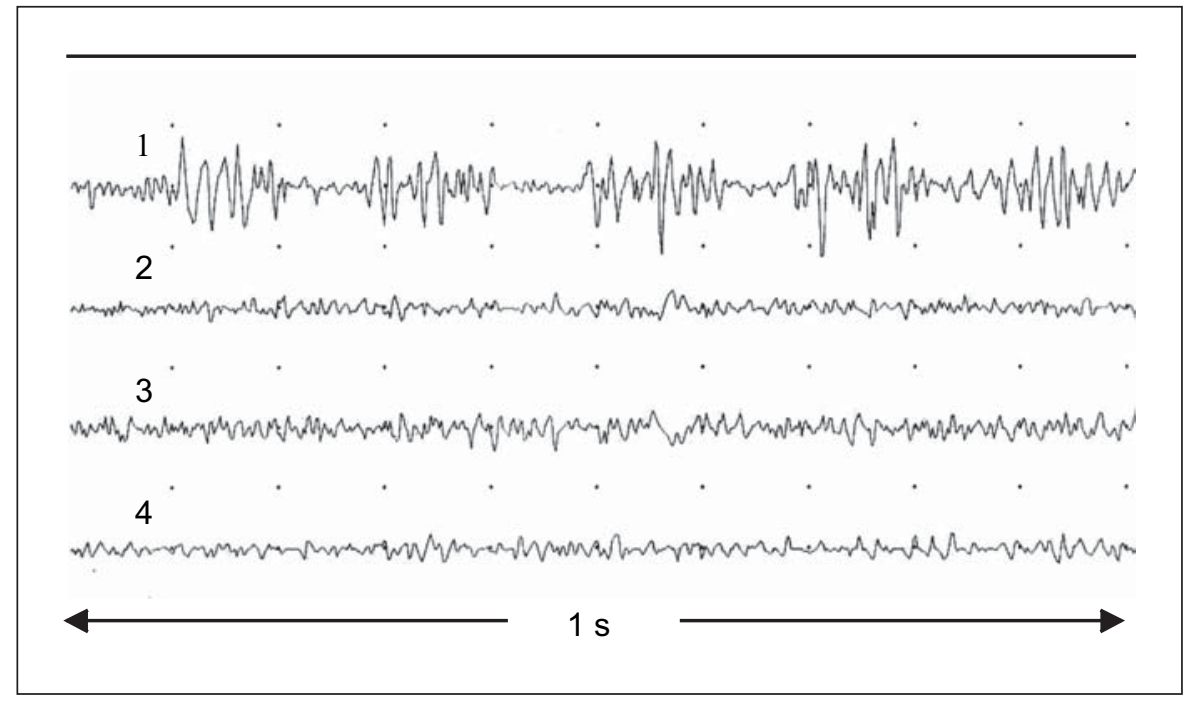




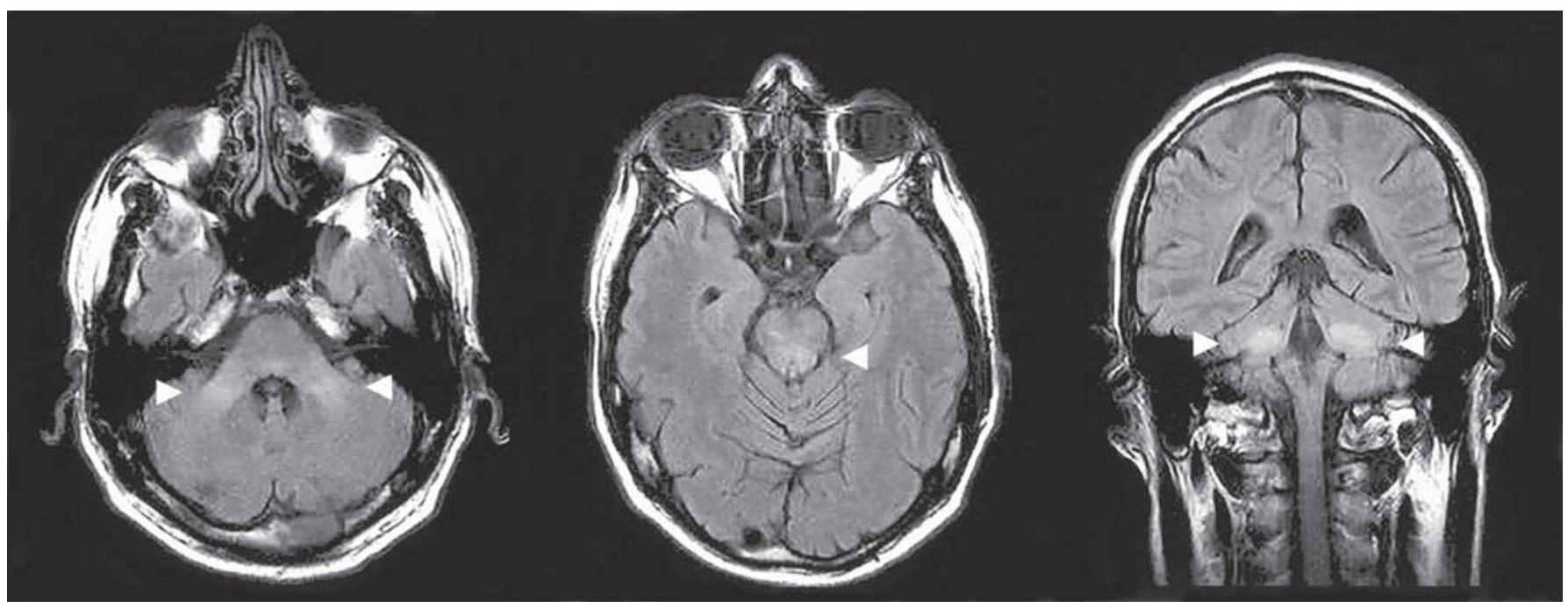

Fig. 2. Brain MRI shows bilateral hyperintensities (arrows) in the mesencephalon, the posterior pons, the cerebellar peduncles and slightly in the cerebellum white matter, as well as a slight cerebellar atrophy (FLAIR sequence). No contrast enhancement was observed.

ing HIV infection. The simultaneous detection of CSF BKV DNA by PCR and its increase in the control analysis may favor BKV as an (additional) etiological agent. Single cases of HIV-associated BKV-induced neurological disease reported a subacute meningoencephalitis in combination with other systemic manifestations and a fatal clinical outcome [9]. In contrast, our patient stabilized despite increased CSV BKV load. Thus, in our opinion, BKV infection does not seem to play an important role in our patient.

During the observation period of 6 months and optimized antiretroviral therapy, neurological deficits lessened, CD4 cell count rose and CSF JCV load became negative. Likewise, beneficial effects of antiretroviral therapy on the survival of AIDS patients with PML have been reported, particularly if symptom progression was halted and CSF JCV load was under control [10].

All in all, our case demonstrates a rare manifestation of HIVassociated PML. We conclude that PML should be considered even in isolated atypical lesions in the posterior fossa in patients with AIDS.

\section{Acknowledgement}

We thank Ms. J. Benson for editing the manuscript.

\section{References}

1 Nath A, Jankovic J, Pettigrew LC: Movement disorders and AIDS. Neurology 1987;37:37-41.

2 Piccolo I, Causarano R, Sterzi R, Klopstock T, Sberna M, Oreste PL, Moioli C, Caggese L, Girotti F: Chorea in patients with AIDS. Acta Neurol Scand 1999;100:332-336.

3 Sporer B, Linke R, Seelos K, Paul R, Klopstock T, Pfister HW: HIV-induced chorea: Evidence for basal ganglia dysregulation by SPECT. J Neurol 2005;252:356-358.

4 Weber T, Klapper PE, Cleator GM, Bodemer M, Luke W, Knowles W, Cinque P, Van Loon AM, Grandien M, Hammarin AL, Ciardi M, Bogdanovic G: Polymerase chain reaction for detection of JC virus DNA in cerebrospinal fluid: A quality control study. European Union Concerted Action on Viral Meningitis and Encephalitis. J Virol Methods 1997;69: 231-237.
5 Whiteman ML, Post MJ, Berger JR, Tate LG, Bell MD, Limonte LP: Progressive multifocal leukoencephalopathy in $47 \mathrm{HIV}$-seropositive patients: Neuroimaging with clinical and pathologic correlation. Radiology 1993; 187:233-240.

6 Vengud E, Jacquy J, Vanderkelen B, Manto MU: High-frequency synchronous bursts firing associated with asynchronous midbrain tremor. Rev Neurol (Paris) 2001;157:682-687.

7 Arai Y, Tsutsui Y, Nagashima K, Shinmura Y, Kosugi T, Wakai M, Nishikage H, Yamamoto J: Autopsy case of the cerebellar form of progressive multifocal leukoencephalopathy without immunodeficiency. Neuropathology 2002;22:48-56.

8 Du Pasquier RA, Corey S, Margolin DH, Williams K, Pfister LA, De Girolami U, Mac Key JJ, Wuthrich C, Joseph JT, Koralnik IJ: Productive infection of cerebellar granule cell neurons by JC virus in an HIV+ individual. Neurology 2003;61:775-782.

9 Vallbracht A, Lohler J, Gossmann J, Gluck T, Petersen D, Gerth HJ, Gencic M, Dorries K: Disseminated BK type polyomavirus infection in an AIDS patient associated with central nervous system disease. Am J Pathol 1993;143:29-39.

10 De Luca A, Giancola ML, Ammassari A, Grisetti S, Paglia MG, Gentile M, Cingolani A, Murri R, Liuzzi G, Monforte AD, Antinori A: The effect of potent antiretroviral therapy and JC virus load in cerebrospinal fluid on clinical outcome of patients with AIDS-associated progressive multifocal leukoencephalopathy. J Infect Dis 2000;182:1077-1083.

Dr. B. Sporer, Department of Neurology

Ludwig Maximilians University, Marchioninistrasse 15

DE-81377 Munich (Germany)

Tel. +49 897095 5821, Fax +49 8970956673

E-Mail bsporer@nefo.med.uni-muenchen.de 